\title{
Penyuluhan Kelompok Pedagang Kaki Lima melalui Kebersihan Lingkungan sebagai Upaya Peningkatan Ekonomi dan Kesehatan Masyarakat
}

\author{
Counseling of Street Vendors Group through Environmental Cleanliness as Efforts to Improve \\ Economy and Public Health
}

\section{Iin Nurbudiyani* \\ Endang Sri Suyati}

Arna Purtina

Department of Economic Education, Universitas Muhammadiyah Palangkaraya, Palangka Raya, Central Kalimantan, Indonesia

*email: iin_nurbudiyani@yahoo.co.id

\section{Kata Kunci}

Penyuluhan

PKL

Kebersihan Lingkungan

Peningkatan Ekonomi

Kesehatan

Keywords:

Counseling

Street vendors

Environmental hygiene

Economic improvement

Health

Received: January 2020

Accepted: March 2020

Published: March 2020

\begin{abstract}
Abstrak
Pada saat terdengar istilah Pedagang Kaki Lima (PKL), terlintas dalam pikiran adalah kondisi yang kumuh, kotor, tidak teratur, hitam, dekil, tidak sehat, tanpa tarif harga menu makanan atau minuman. Kemudian keberadaannya mengganggu pemandangan, menyita trotoar jalan, sehingga menjadi sasaran dan objek petugas ketertiban karena berjualan di pinggir jalan yang bukan area untuk jualan. Dikejar satpol PP untuk ditertibkan, hilang sebentar muncul lagi, kucing-kucingan dengan petugas trantib. Apalagi di tengah kota, jalan protokol, yang sering untuk lewat tamu-tamu pejabat atau tamu-tamu negara. Pedagang Kaki Lima disatu sisi mengganggu mata, dengan gerobak yang sudah lusuh, dekil, namun dibutuhkan keberadaannya oleh masyarakat. Mereka sering disebut sebagai pelaku sektor informal yang tetap bertahan tidak rentan dengan gejolak nilai dolar. Buktinya pada saat krisis moneter perusahaan pada gulung tikar, namun PKL tetap eksis berjualan. Bahkan para pegawai yang terkena PHK dan dirumahkan, berpindah haluan menjadi PKL. Di Kota Palangkaraya Pedagang kaki Lima hampir bias ditemukan disetiap sudut jalan, Perda No. 13 Tahun 2009 yang mengatur tentang Pengaturan, Penertiban, dan Pengawasan Pedagang Kaki Lima belum berjalan secara maksimal. Melalui pengabdian masyarakat ini tim pengabdian ingin ikut berpartisipasi memberikan penyuluhan mengenai betapa bermanfaatnya menjaga dan pengaturan lingkungan PKL sebagai upaya peningkatan Ekonomi dan kesehatan masyarakat.
\end{abstract}

\begin{abstract}
When you hear the term Street Vendors (PKL), it comes to mind that conditions are slum, dirty, irregular, black, dirty, unhealthy, without tariffs on the price of food or drink menus. Then its existence disturbed the view, seized the sidewalks of the road so that it became the target and object of the order officers because it was selling on the side of the road which was not an area for sale. The police pursued to be disciplined, disappeared briefly appeared again, cat and mouse with trantib officers. Especially in the middle of the city, the protocol road, which is often for officials to pass guests or state guests. Street vendors on one side disturb the eyes, with carts that are worn, dirty, but their existence is needed by the community. They are often referred to as informal sector actors who remain vulnerable to the fluctuation of the dollar. The proof at the time of the company's financial crisis went bankrupt, but street vendors still exist to sell. Even employees who are laid off and laid off become street vendors. In Palangkaraya Street Vendors are almost biased to be found on every street corner, Perda No. 13 of 2009 which regulates the Arrangement, Ordering, and Supervision of Street Vendors seems to have not run optimally. Through this community service, we would like to participate in providing counseling on how beneficial it is to maintain and regulate the street vendors' environment as an effort to improve the economy and public health.
\end{abstract}




\section{PENDAHULUAN}

Di Kota Palangkaraya Pedagang Kaki Lima (PKL) adalah sektor informal yang bisa kita temukan disetiap sudut dan disepanjang jalan. PKL adalah istilah untuk menyebut penjaja dagangan yang melaksanakan kegiatan komersial di atas daerah milik jalan (trotoar) yang seharusnya diperuntukkan untuk pejalan kaki (Saputra \& Indrawati, 2014). Meskipun Perda No. 13 Tahun 2009, mengenai Pengaturan, Penertiban dan Pengawasan PKL sudah diterapkan namun kenyataannya belum bisa dilaksanakan secara maksimal.

Pedagang Kaki Lima di satu sisi mengganggu pemandangan mata, dengan gerobak yang sudah lusuh, dekil namun dibutuhkan oleh masyarakat keberadaannya. Pedagang Kaki Lima sering disebut sebagai pelaku sektor informal yang tetap bertahan tidak rentan oleh gejolak nilai dolar (Ismanidar et al., 2016). Buktinya di tahun 1998 saat krisis moneter banyak perusahaan pada gulung tikar namun para PKL tetap pada berjualan. Bahkan pegawai perusahaan yang terkena PHK atau dirumahkan banyak yang berpindah haluan menjadi PKL, sesungguhnya roda itu selalu berputar, kadang diatas dan suatu saat berada dibawah (Ermandara, 2016).

Istilah PKL sudah dikenal sejak penjajahan jaman Belanda dahulu, yang membuat Peraturan Pemerintah bahwa setiap jalan raya yang dibangun harus menyediakan saran untuk pejalan kaki. Lebar ruas untuk pejalan kaki adalah harus lima kaki atau sekitar satu setengah meter (Hadinata \& Ruchimat, 2018). Namun ada pula pihak yang iseng dengan membuat penjelasan bahwa PKL itu membawa barang dagangan dengan gerobak yang mempunyai tiga (3) kaki, di depan atau di belakang satu, kanan dan kiri masing-masing satu. Kemudian menjadi lima (5) kaki karena ditambah dua (2) kaki dari orang yang mendorong gerobagnya. Jadilah namanya menjadi pedagang yang mempunyai kaki lima, tiga kaki untuk gerobag dan dua kaki milik yang mendorong gerobag, yang sewaktu-waktu dapat berjalan untuk berpindah tempat.

Seiring dengan perkembangan jumlah penduduk, meningkatnya perekonomian, dengan luas jalan yang sama, maka area untuk berjalan kaki menjadi lebih sempit atau tidak ideal lagi. Bahkan hilang sama sekali karena dihabiskan untuk jualan PKL lengkap dengan tenda, meja, kursi, tempat cuci, kompor gas dan lainlainnya (Rochaida, 2016). Akibatnya para pejalan kaki haknya tanpa disadari telah dirampas oleh para PKL. Mirisnya lagi bila ada penertiban PKL berpotensi menimbulkan gesekan sosial (Puspitasari, 2010). Alasannya sepetak trotoar yang seharusnya untuk pejalan kaki dan untuk umum itu mempunyai nilai ekonomis yang disewakan oleh oknum yang mengatasnamakan penguasa didaerah tersebut. Semakin ramai dan laris dagangannya harga sewa juga semakin naik per tahunnya (Hendra, 2019).

Keberadaan PKL yang berjualan di trotoar walaupun dibutuhkan, diakui mengganggu lingkungan sehingga wajar kalau rutin selalu dilakukan penertiban (Asiyah, 2012). Setiap Pemerintah Daerah semestinya suda mempunyai payung hukum dengan Peraturan Daerah tingkat Provinsi maupun tingkat Kabupaten/Kota tentang PKL. Artinya ketika petugas trantib menertibkan itu ada dasar hukumnya, karena keberadaan PKL yang mengganggu lingkungan (sosial, kesehatan, ketertiban) (Pulungan, 2017). Secara sosial ada gesekan kepentingan antara petugas trantib yang menjalankan tugas untuk menertibkan, sementara dari sisi PKL terpaksa berjualan ditrotoar untuk mencari sesuap nasi demi menghidupi keluarganya.

Jika kita lihat dari segi kesehatan limbah sisa-sisa makanan, air bekas cucian piring gelas sendok menyebabkan genangan air comberan di selokan atau 
got-got yang menimbulkan bau tidak sedap. Air cucian yang tidak mengalir dari kran berpotensi dan dapat mengganggu kesehatan. Selain itu makanan yang dijual dipinggir-pinggir jalan yang kadang tidak ditutup dapat tercemar oleh asap knalpot, debu dan lalat yang berterbangan. Kemudian ketertiban lalu lintas juga bisa terganggu oleh parkir kendaraan pembeli atau konsumen yang menyita ruang jalan sering menimbulkan kemacetan lalu lintas.

Boleh diakui pemerintah maupun para penggerak ekonomi kerakyatan sudah mencari jalan tengah yaitu dengan merelokasi pada tempat yang sudah di tentukan, namun muncul persoalan baru lagi yaitu para PKL merasa merugi karena sepi pembeli dengan alasan tempat yang tidak strategis. Menertibkan PKL memang tidak mudah perlu secara komprehensif, berkelanjutan dan sinergi dengan berbagai pihak dan instansi untuk mencari jalan keluarnya, bagaimanapun PKL juga sebagai warga negara yang mempunyai hak untuk hidup dengan layak dan diakui keberdaannya (Saragih, 2016).

\section{METODOLOGI}

Kegiatan pengabdian kepada masyarakat dilaksanakan di Aula Pimpinan Wilayah Muhammadiyah Palangkaraya yang berlokasai di Jalan RTA Milono Km 1,5 Komplek Perguruan Universitas Muhammadiyah Palangkaraya, yang mudah dijangkau dan dikenal oleh para PKL.

Metode kegiatan Pengabdian ini adalah berupa penyuluhan, yang dilanjutkan implementasi dalam kegiatan berdagang. Kegiatan pengabdian dilakukan dalam 3 (tiga) tahapan, yaitu: (1) Tahap pertama yaitu, pengenalan mengenai perda PKL dan maksud dan tujuan kegiatan pengabdian, yaitu bahwa kegiatan PKL ini ada peraturan dari pemerintah daerah yang mengaturnya. Bagaimana dengan para PKL ini apakah pernah membacanya dan mendapat penjelasan dari yang petugas. Pada tahap ini tim pengabdian memperkenalkan diri, dengan cara mendatangi PKL yang berjumlah 20 orang yang mereka berada dan berdagang disepanjang Jalan Cilik Riwut Km 1,0. Tim pengabdian menjelaskan maksud kedatangan dan kegiatan kemudian memperkenalkan dan Perda No. 13 Tahun 2009 yang sudah dipersiapkan fotocopynya, (2) Tahap kedua yaitu, diadakan penyuluhan langsung kepada para PKL yang berjumlah 20 orang tadi, mengenai Perda No. 13 Tahun 2009 dan bagaimana dampaknya kalau perda tersebut kita patuhi bagi kesejahteraan ekonomi dan bagi kesehatan. Pada tahap ini tim pengabdian mengundang para PKL yang berjumlah 20 orang, lalu dijelaskan mengenai Perda No. 13 Tahun 2009, bagaimana cara berjualan yang sehat di pinggir jalan dan yang lain-lainnya, (3) Untuk selanjutnya tahap yang ketiga yaitu, bagaimana implementasinya di lapangan, tim Pengabdian lalu melakukan evaluasi di lapangan dengan cara mendatangi ke lokasi berdagang apakah mereka sudah menerapkan hal yang telah tm pengabdianjelaskan pada saat penyuluhan. Tim pengabdian selanjutnya memberikan hadiah bagi mereka yang menerapkannya dengan benar sesuai dengan apa yang ada di Perda No. 13 Tahun 2009. Tim pengabdian mengambil 6 peserta yang terbaik yaitu, terbaik 1, 2 dan 3 kemudian terbaik harapan 1, 2 dan 3. Dari jumlah peserta yang 20 orang itu dengan hadiah yang sudah dipersiapkan, (4) Untuk yang punya dan bisa menggunakan IT silahkan membuka website resmi pemerintah kota palangkaraya.

\section{HASIL DAN PEMBAHASAN}

Pengenalan Perda PKL dan Pengenalan kegiatan

Sasaran atau mitra pada kegiatan pengabdian ini adalah para PKL yang beragam latar belakang dan pendidikannya. IPTEK yang diberikan kepada para 
pedagang adalah pemahaman dan penerapan Peraturan Daerah Kota Palangkaraya No. 13 Tahun 2009, tentang Pengaturan, Penertiban dan Pengawasan Pedagang Kaki Lima, serta kesadaran untuk selalu menjaga kebersihan lingkungan demi kesehatan dan kesejahteraan bersama. Untuk menghindari kecurigaan dan ketidaktahuan nanti juga dijelaskan maksud dan tujuan tim pengabdian melakukan kegiatan pengabdian ini.

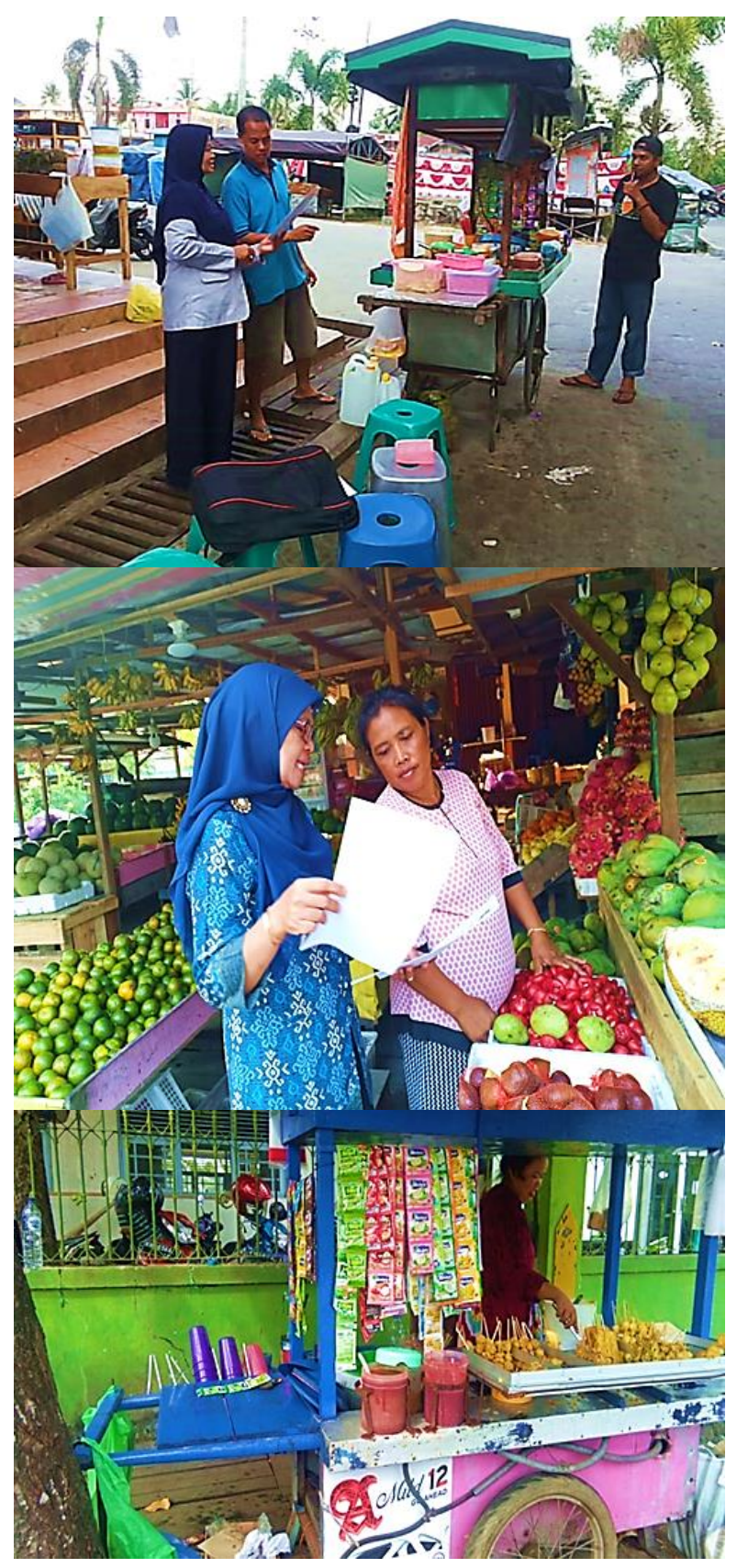

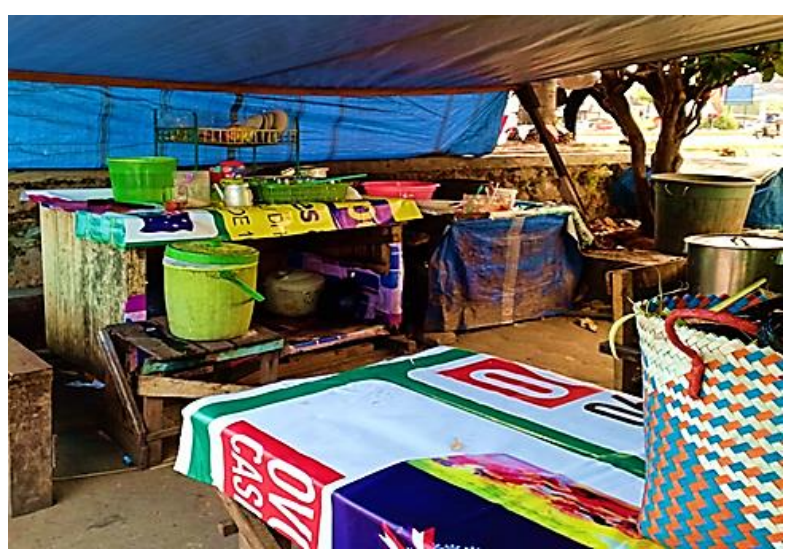

Gambar 1. Pengenalan Perda PKL kepada PKL dan Kondisi tempat dagangan PKL

\section{Praktik Penyuluhan Kegiatan Pengabdian}

Dalam kegiatan penyuluhan IPTEK yang disajikan adalah bagaimana tata cara mendirikan dan melakukan usaha dagang atau bisnis dengan benar tidak melanggar atauran dan yang sesuai dengan Peraturan Daerah setempat. Syarat-syarat apa yang harus dipatuhi dan larangan-larangan apa yang tidak boleh dilakukan. Bagaimana berdagang yang sehat dipinggir jalan. Sehingga mereka bisa berdagang dengan tenang tanpa harus was-was diusir dan kucing-kucingan dengan petugas.

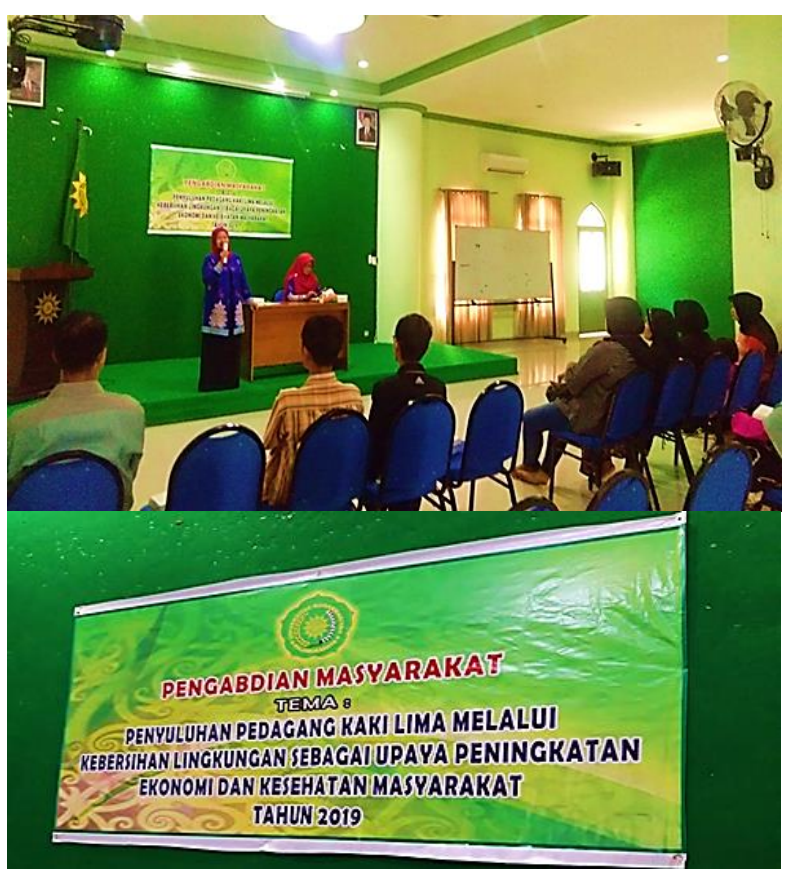




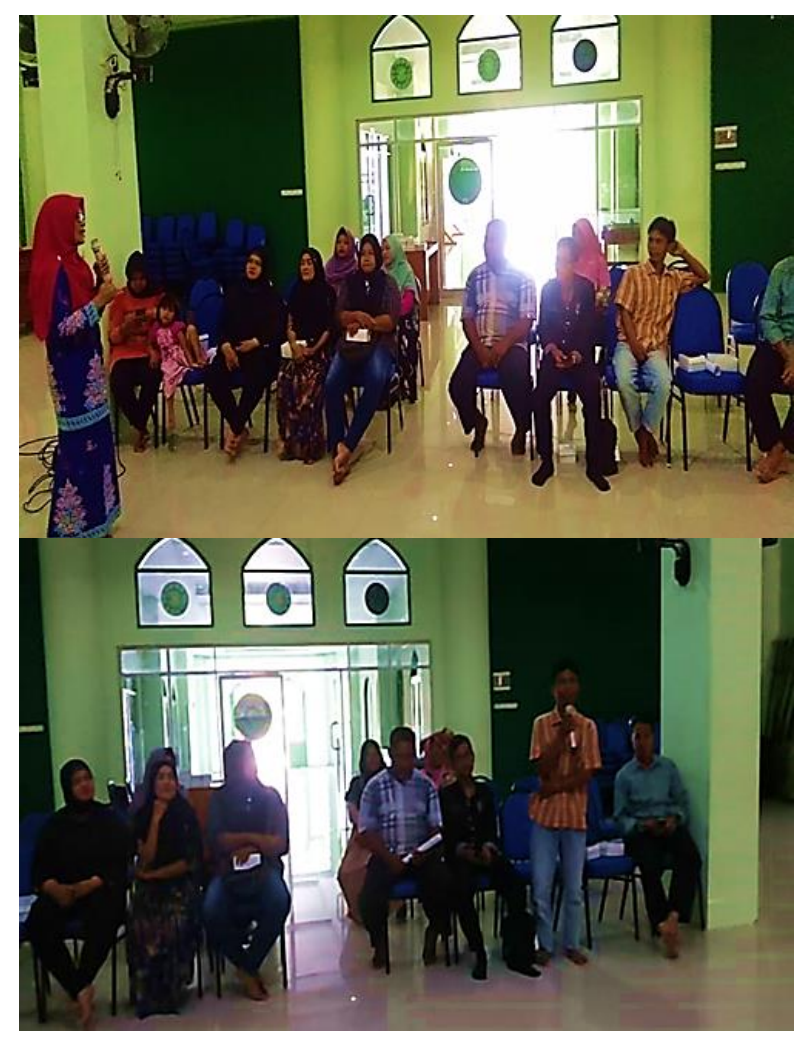

Gambar 2. Kegiatan penyuluhan kepada PKL

\section{Evaluasi dan Monitoring}

Yang dimaksud IPTEK dalam evaluasi disini adalah sejauh mana para pedagang itu mentaati dan melaksanakan sesuai dengan apa yang ada pada Perda No. 13 Tahun 2009, yang sudah disampaikan pada saat kegiatan penyuluhan. Tim Pengabdian lalu memberikan hadiah pada PKL yang melaksanakan Perda dengan benar dan baik.

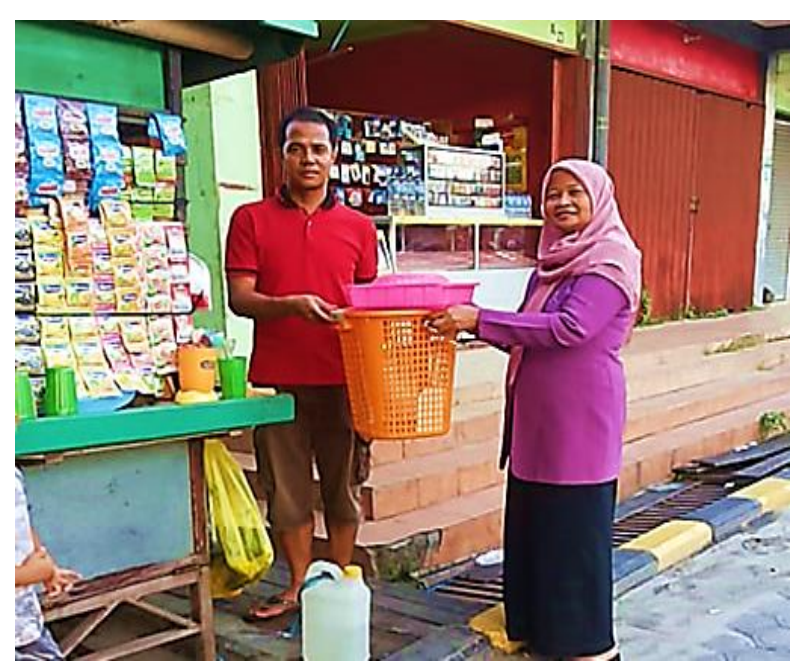

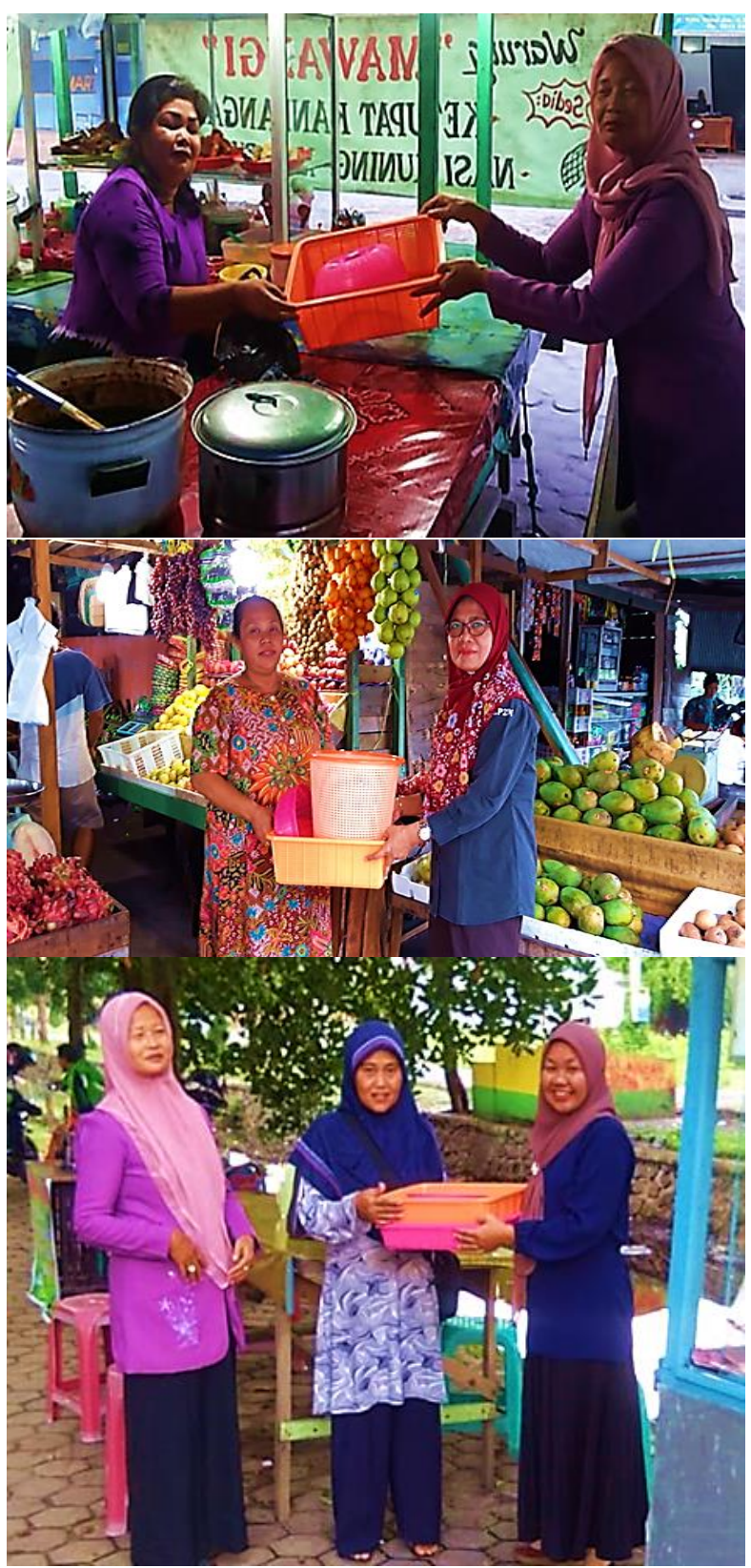

Gambar 3. Evaluasi kegiatan dan pemberian souvenir kepada PKL

\section{KESIMPULAN}

Bersadasarkan pengbdian masyarakat yang telah dilakukan dapat disimpulkan bahwa pemahaman dan penerapan Peraturan Daerah Kota Palangkaraya No. 13 Tahun 2009, tentang Pengaturan, Penertiban dan Pengawasan Pedagang Kaki Lima, serta kesadaran untuk selalu menjaga kebersihan lingkungan demi kesehatan dan kesejahteraan bersama, dan adanya praktik penyuluhan kegiatan pengabdian yang sajikan 
adalah bagaimana tata cara mendirikan dan melakukan usaha dagang atau bisnis dengan benar tidak melanggar aturan dan yang sesuai dengan Peraturan Daerah setempat. Syarat-syarat apa yang harus dipatuhi dan larangan-larangan apa yang tidak boleh dilakukan. Selanjutnya para PKL di Evaluasi dan Monitoring sejauh mana para pedagang itu mentaati dan melaksanakan sesuai dengan apa yang ada pada Perda No. 13 Tahun 2009. Tim pengabdian memberikan hadiah pada PKL yang melaksanakan Perda dengan benar dan baik. Kegiatan pengabdian dengan tema Penyuluhan Kelompok PKL Melalui Kebersihan Lingkungan Sebagai Upaya Peningkatan Ekonomi dan Kesehatan Masyarakat, mampu memberi kontribusi terhadap visi dan misi pembangunan Kota Palangkaraya. Pengabdian kepada masyarakat ini perlu kiranya dilanjutkan sesuai dengan usulan dari pihak PKL guna menjaga dan pengaturan lingkungan PKL sebagai upaya peningkatan ekonomi dan kesehatan masyarakat yang lebih baik, khususnya bagi Kota Palangkaraya Provinsi Kalimantan Tengah. Agar kiranya kebaikan ini tidak bersifat sementara namun mendapatkan tindak lanjutan yang lebih dalam lagi.

\section{UCAPAN TERIMA KASIH}

Ucapan terima kasih kepada Lembaga Penelitian dan Pengabdian Masyarakat Universitas Muhammadiyah Palangkaraya atas bantuan dana untuk pelaksanaan pengabdian masyarakat ditahun 2019. Terima kasih pula diucapkan kepada pihak PKL atas bantuan dan izinnya untuk melaksanankan kegiatan ini sehingga berjalan dengan lancar dan tak lupa pula diucapkan terima kasih karena meluangkan waktunya untuk melakukan kelengkapan hasil akhir dalam pelaksanaan pengmas ini serta ucapan terima kasih kepada semua yang terlibat semoga selalu dalam lindungan Allah.

\section{REFERENSI}

Asiyah, U. 2012. Pedagang Kaki Lima Membandel di Jawa Timur. Masyarakat, Kebudayaan dan Politik. 25(1):47-55.

Ermandara, D. 2016. Risiko Bisnis Dan Siasat Pedagang Kelana: Studi Kasus Pasar Jumat Asy-Syiraj Di Kota Bandung. Umbara: Indonesian Journal of Anthropology. 1(1):13-25. https://doi.org/10.24198/umbara.v1i1.9601

Hadinata, M., Ruchimat, T. 2018. Analisis Terhadap Kebijakan Pemerintah Provinsi DKI Jakarta Tentang Penutupan Jalan Jati Baru Raya Untuk Pedagang Kaki Lima. Jurnal Hukum Adigama. 1(2):1-25.

Hendra, D. 2019. Solidaritas Sosial Pedagang Kaki Lima terhadap Tingkah Laku Konsumen di D.I Yogyakarta. Populika. 7(1):1-11.

Ismanidar, Amirullah, Usman, S. 2016. Persepsi Masyarakat Terhadap Pedagang Kaki Lima Di Kota Banda Aceh. Jurnal Ilmiah Mahasiswa Pendidikan Kewarganegaraan. 1(1):147-157.

Pulungan, M.S. 2017. Perlindungan Hukum dan Pembinaan Pedagang Kaki Lima di Balikpapan. Matra Pembaruan: Jurnal Inovasi Kebijakan. 1(1):11-21. https://doi.org/10.21787/mp.1.1.2017.11-21

Puspitasari, D.E. 2010. Penataan Pedagang Kaki Lima Kuliner untuk Mewujudkan Fungsi Tata Ruang Kota di Kota Yogyakarta dan Kabupaten Sleman. Mimbar Hukum. 22(10):588-606. https://doi.org/10.22146/jmh.16244

Rochaida, E. 2016. Dampak Pertumbuhan Penduduk Terhadap Pertumbuhan Ekonomi Dan Keluarga Sejahtera Di Provinsi Kalimantan Timur. Forum Ekonomi: Jurnal Ekonomi, Manajemen dan Akuntansi. 18(1):14-24. http://dx.doi.org/10.29264/jfor.v18i1.42

Saputra, R.B., Indrawati. 2014. Profil Pedagang Kaki Lima (PKL) Yang Berjualan Di Badan Jalan (Studi Di Jalan Teratai Dan Jalan Seroja Kecamatan Senapelan). Jurnal Online Mahasiswa Fakultas Ilmu Sosial dan Ilmu Politik Universitas Riau. 1(2):1-15.

Saragih, R.T. 2016. Implementasi Perda Kota Surabaya No. 9 Th 2014 Tentang Penyediaan Ruang 
Bagi Pedagang Kaki Lima Di Pusat Perbelanjaan Dan Pusat Perkantoran Di Kota Surabaya (Studi Kasus Di Kawasan Terminal Bratang Kecamatan Gubeng). JPAP (Jurnal Penelitian Administrasi Publik). 2(1):33-50. https://doi.org/10.30996/jpap.v2i01.699 